in vivo $35: 95-103(2021)$

doi:10.21873/invivo.12236

Review

\title{
The Angiotensin-converting Enzyme Insertion/ Deletion Polymorphism as a Common Risk Factor for Major Pregnancy Complications
}

\author{
IPHIGENIA GINTONI ${ }^{1,2}$, MARIA ADAMOPOULOU ${ }^{3}$ and CHRISTOS YAPIJAKIS ${ }^{1,2}$ \\ ${ }^{1}$ Unit of Orofacial Genetics, $1^{\text {st }}$ Department of Paediatrics, School of Medicine, \\ "Agia Sophia" Children's Hospital, National Kapodistrian University of Athens, Athens, Greece; \\ ${ }^{2}$ Department of Molecular Genetics, "Cephalogenetics" Center, Athens, Greece; \\ ${ }^{3}$ Department of Biomedical Sciences, University of West Attica, Athens, Greece
}

\begin{abstract}
Idiopathic pregnancy complications pose a major threat to both maternal and fetal health worldwide. Numerous studies have implicated the role of the renin-angiotensin system (RAS) in the development of obstetric syndromes, since it is crucial for the uteroplacental function. A major RAS component is the angiotensin-converting enzyme (ACE), which hydrolyses angiotensin I to angiotensin II, and not only regulates arterial pressure, but also fibrinolytic activity, indirectly, through the expression of plasminogen activator inhibitor-1. A key functional polymorphism of the ACE gene is the insertion/deletion (I/D) polymorphism, which affects gene expression and product levels, and can therefore lead to high blood pressure and/or reduced fibrinolytic activity. These can cause major pregnancy complications, such as preeclampsia, recurrent pregnancy loss and preterm birth. This review discusses how the ACE I/D is associated with susceptibility towards pregnancy complications, on its own or in combination with other functional gene polymorphisms such, as the angiotensin II receptor type 1 (AT1R) A1166CC, angiotensin II receptor type 2 (AT2R) G1332A, plasminogen activator inhibitor-1 (PAI-1) 4G/5G, matrix metallopeptidase9 (MMP-9) C1562T, angiotensinogen (AGT) M235T, renin (REN) 83A/G, factor XIII (F13) Val34Leu and endothelial nitric oxide synthase (eNOS) $4 a / b$.
\end{abstract}

This article is freely accessible online.

Correspondence to: Christos Yapijakis, Department of Molecular Genetics, Cephalogenetics Center, Philaretou 88, Kallithea 17675, Athens, Greece. Tel: +30 2109595772, e-mail: cyapi@med.uoa.gr

Key Words: ACE, renin-angiotensin system, obstetrical complications, preeclampsia, miscarriage, pregnancy loss, preterm birth, review.
Most pregnancies worldwide reportedly progress uneventfully, however, up to $10-15 \%$ of pregnant women may experience pregnancy complications, which may threaten both their own as well their fetus' health or even life $(1,2)$. Major obstetrical complications can be triggered by health problems women face before pregnancy or conditions that arise during gestation. There are several factors that cause pregnancy complications, including some that are idiopathic or genetic, therefore, their prior knowledge may alert the obstetrician-gynecologist to adopt preventive measures $(1,2)$.

Mounting evidence in recent years has revealed a key role of the Renin-Angiotensin System (RAS) in normal gestational development as well in major obstetric complications, in addition to its classical role in regulating blood pressure and electrolyte balance $(3,4)$. While most RAS components increase during a typical normal pregnancy due to hormonal changes contributing to the regulation of the uteroplacental blood flow, embryo implantation and placentation (3-5), the angiotensin-converting enzyme (ACE) is the only major RAS component that declines naturally (4).

In addition to its indirect role in blood pressure by converting angiotensin I to angiotensin II, ACE is also responsible for the balanced cooperation between the processes of coagulation and fibrinolysis during gestation in uncomplicated pregnancies $(6,7)$. In cases of abnormally high expression due to certain genetic variants, the balance between coagulation and fibrinolysis becomes disturbed and the pregnancy may enter a high-risk territory for the development of some major obstetrical complications (3-9). Recent evidence suggests that most of these high-risk pregnancies may be anticipated and managed using prophylactic measures, especially if there is involvement of ACE, the central player of the RAS system. 
The most common and well-studied polymorphism in the $A C E$ gene is the insertion/deletion (I/D) polymorphism, which may result, respectively, in lower or higher concentrations of the circulating ACE and, thus, in different levels of enzymic activity $(10,11)$. Increased ACE activity results in reduced fibrinolysis and increased risk of thrombosis, alongside with elevated blood pressure. All these can negatively affect the uteroplacental health status and thus the outcome of the pregnancy itself $(5-7,10,12)$.

In order to receive proper medical attention at an early stage, it is important that the genetic predisposition of a woman towards obstetric syndromes is estimated by the usage of established molecular markers. The current review will discuss findings regarding the role of the $A C E \mathrm{I} / \mathrm{D}$ polymorphism in major obstetrical syndromes, including preeclampsia, recurrent pregnancy loss, preterm birth and its influence in the health status of premature neonates. Furthermore, this study will shed some light on how the ACE I/D may affect the susceptibility towards the above complications when combined with other well-studied polymorphisms of other genes.

\section{The Renin - Angiotensin System (RAS)}

One of the most significant systems controlling homeostasis and function in the human body is RAS, a signaling cascade that plays a key role in the regulation of arterial pressure, electrolyte balance, extracellular fluid volume, tissue perfusion, inflammation and fibrosis $(4,12)$. RAS responds independently in many organs, but it can function locally either in an autonomous manner or in cooperation with the circulating RAS in order to regulate cell growth, differentiation and function, as well as to participate in inflammatory responses $(5,13,14)$.

The activation of the RAS, which may raise blood pressure by almost $30 \mathrm{mmHg}$, is triggered by loss of blood volume, a sudden drop in blood pressure in cases of haemorrhage or dehydration, or decreased filtration flow rate (15). All those cases stimulate the macula densa, a region of specialized epithelial cells that are tightly packed in the kidney and are included in the juxtaglomerular apparatus (16). That stimulation results in the signal transduction towards the juxtaglomerular epithelioid cells, which are located in the medial layer of renal afferent arterioles and synthesize, store and release renin (Figure 1). Renin is an enzyme consisting of 340 amino acids (aa) in its active form. Once it is released into the bloodstream, renin cleaves angiotensinogen (AGT), a 453 aa $\alpha$-2-globulin of the serpin family that is naturally produced by the liver and released into the circulatory system $(14,17)$. Renin hydrolyses AGT into angiotensin I (Ang I), which is then converted into angiotensin II (Ang II) by ACE, a zinc metallopeptidase bound to the plasma membrane of vascular endothelial cells mostly in lungs and kidneys $(14,18)$.
Ang II is a multifunctional octapeptide hormone that stimulates events, such as narrowing of blood vessels, contraction of smooth muscle cells, renal retention of sodium and water, sympathetic nervous system activity, and aldosterone secretion by the adrenal glands (15). Ang II exerts its effects by binding to angiotensin II type 1 receptor (AT1R) and angiotensin II type 2 receptor (AT2R). Both receptors belong to the $\mathrm{G}$ protein-coupled superfamily of receptors (GPCRs) (19). AT1R is the paramount angiotensin receptor, accounting for most of Ang II signalling and hemodynamic effects $(4,20)$, while AT2R is mainly expressed in fetal tissues and in the reproductive tract of adults (5).

At a later stage, angiotensin II is degraded into the heptapeptide angiotensin (1-7) by the angiotensin converting enzyme 2 (ACE2), another transmembrane zinc metallopeptidase similar to the ACE but with a different substrate specificity (21). ACE2 combats the effects of Ang II through the activation of the $\mathrm{G}$ protein-coupled MAS receptor by its product Ang (1-7), which may be found both in the plasma and tissues $(21,22)$.

\section{The Role of RAS in Pregnancy}

RAS is altered in gestation due to endocrine secretions from the ovary, placenta, and decidua $(3,4)$. More specifically, during early stages of pregnancy estrogen-induced rise in AGT levels directly leads to an increase in the levels of released angiotensin II (3). Expression of RAS components takes place in the uteroplacental unit, indicating the importance of its local function. The uteroplacental RAS contributes highly to the regeneration of the endometrium after shedding, to decidualization, implantation and placentation (5). In addition, local RAS is also involved in the synthesis of prostaglandin, the secretion of oestradiol and the blood flow regulation of the uterus and the placenta (5).

\section{The Angiotensin-converting Enzyme (ACE) and its gene}

ACE is a type I transmembrane monomeric glycoprotein that acts as a zinc metallopeptidase to catalyze the conversion of Ang I to Ang II as a major component of RAS $(14,21)$. In addition, it degrades bradykinin and substance $\mathrm{P}$, two local inflammatory mediators $(14,21)$. The gene encoding angiotensin-converting enzyme $A C E$, consists of 25 introns and 26 exons, it is $21 \mathrm{~kb}$ long and is located in the long arm of chromosome 17 (locus 17q23.3) (23). ACE derives from a tandem duplication of an ancestral gene; therefore, exons 411 and 17-24 encode a two-domain protein with an $\mathrm{N}$-domain and a C-domain $(23,24)$. There is a signal peptide at the $\mathrm{N}$ terminus of the enzyme, which is essential to break through the endoplasmic reticulum, while the $\mathrm{C}$-terminal domain contains a hydrophobic transmembrane anchor. The catalytic activity of the membrane-anchored ectoenzyme ACE is 


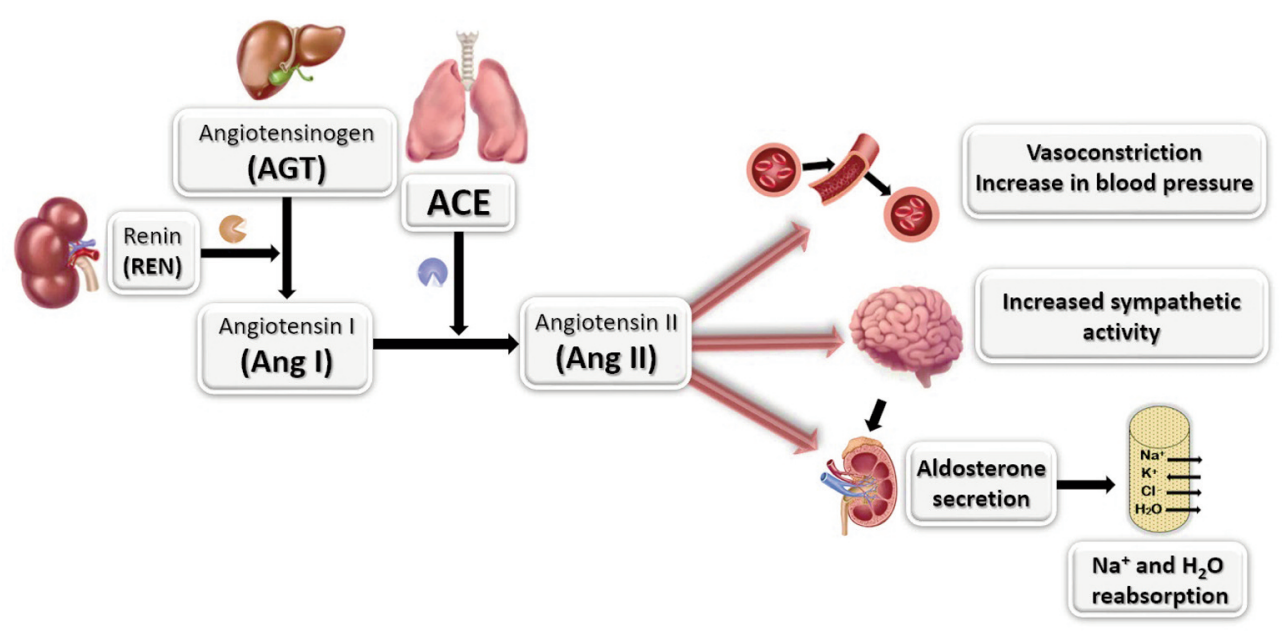

Figure 1. The various functions of the renin-angiotensin-system (RAS). Released into the bloodstream by the kidney, renin cleaves angiotensinogen, which is produced in the liver, and converts it to angiotensin I. The angiotensin-converting enzyme (ACE), which is mostly present in the lungs and kidneys, converts angiotensin I into angiotensin II. After binding to its receptors AT1R and AT2R in several tissues, angiotensin II stimulates various events, such as smooth muscle cell vasoconstriction and narrowing of blood vessels, increased sympathetic nervous system activity, and stimulation of the adrenal cortex, to secrete the hormone aldosterone that promotes renal retention of salt and water.

determined by the M2-type zinc metallopeptidase motif HisGluXXHis, with a glutamate approaching the C-terminus by 23-24 residues. The histidine residues and the glutamate are the ligands for the zinc cofactor $\left(\mathrm{Zn}^{+2}\right)$, which is mandatory for the catalytic capacity of ACE (24).

\section{The Insertion/Deletion (I/D) Polymorphism in the $A C E$ Gene}

The most common and significant DNA polymorphism detected in the $A C E$ gene is the I/D polymorphism (rs4646994) $(10,25)$. The I/D polymorphism is an insertion or deletion of a $287 \mathrm{bp}$ fragment in intron $16(10,25)$. The D allele is associated with elevated plasma ACE levels and, thus, with enhanced ACE activity (11) More specifically, the homozygotes for the $\mathrm{D}$ allele $(\mathrm{D} / \mathrm{D})$ tend to have twice higher levels of the encoded enzyme circulating in blood plasma in comparison with individuals homozygous for the I allele (I/I), which is linked to the lowest ACE levels (26). Finally, the heterozygotes (I/D) have been shown to have intermediate concentrations of the ACE in plasma and tissues (27).

\section{Effects of Elevated ACE Levels During Pregnancy}

It is well known that after the coagulation system senses an outbreak of bleeding due to vascular damage, the fibrinolytic system clears the vascular obstructions (28). Thus, abnormal changes in fibrinolytic activity and imbalance between the fibrinolysis and coagulation pathways are very likely to disrupt the pregnancy's normal development, especially since hypercoagulability occurs naturally during pregnancy, increasing the possibility of fibrin generation $(6,7,28)$. ACE, in particular, plays a fundamental role in in the fibrinolysis pathway (Figure 2) by influencing the levels of plasminogen activator inhibitor-1 (PAI-1), which is the main controller of the fibrinolytic process, in addition to PAI-2, which is expressed in the placenta (9). Since the $A C E$ I/D and D/D genotypes lead to elevated ACE concentrations in blood and tissue (27), their influence results in higher expression of PAI1. Consequently, levels of fibrinolysis are decreased, leading to the conclusion that ACE may act as a hypofibrinolytic factor if its expression is not normally low $(6,7)$. Quite the reverse, the overexpression of PAI-1, due to elevated ACE concentration, may lead to thrombotic incidents (10).

Uteroplacental RAS is responsible for local vascular resistance and blood flow, since plasma renin concentration is increased during pregnancy culminating during the first trimester (5). The placental blood flow may be reduced through angiotensin II in pregnancies that are complicated by high blood pressure conditions, such as preeclampsia (5, 29 ). Thus, the delivery of nutrients and oxygen to the fetus will be insufficient, negatively influencing its development and increasing the mother's risk of developing further complications like dysfunctional bleeding, endangering the course and outcome of the pregnancy $(5,29)$. Therefore, the $\mathrm{D}$ allele of the $A C E$ I/D polymorphism might influence the uteroplacental and umbilical flows, as shown by a study of women who had previously experienced preeclampsia during different gestation stages (30). According to this study's findings, women carrying the $\mathrm{D} / \mathrm{D} A C E$ genotype tended to 


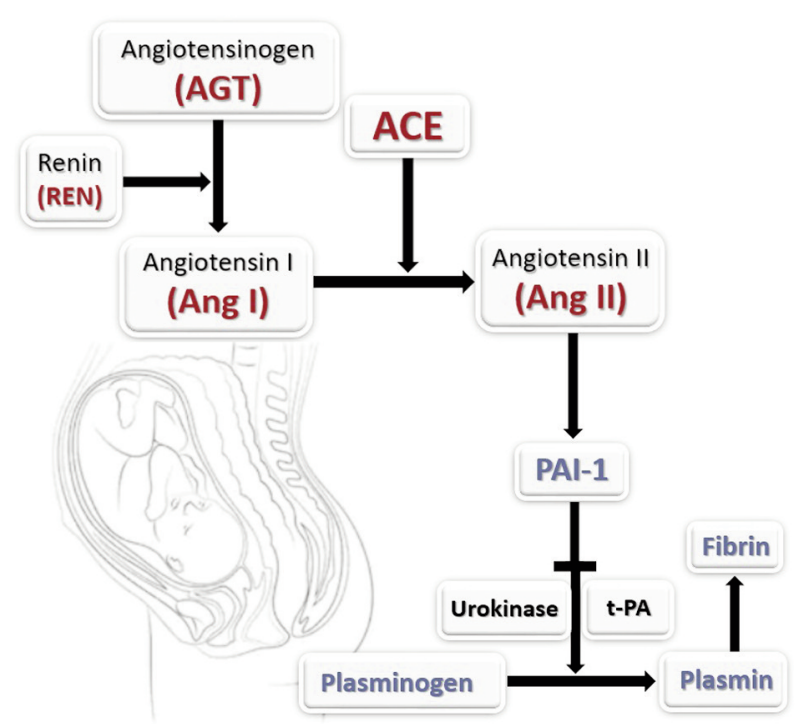

Figure 2. The roles of angiotensin converting enzyme (ACE) and plasminogen activator inhibitor-1 (PAI-1) in pregnancy through the interaction of the RAS with the fibrinolysis pathway. ACE converts angiotensin I to angiotensin II and indirectly regulates the expression of PAI-1 which is the predominant inhibitor of tissue plasminogen activator (tPA) and urokinase. Inactive plasminogen is converted to active plasmin by $t-P A$ and urokinase. Plasmin degrades fibrin and its degradation products act competitively against the process of fibrinogenesis delaying clot formation.

have significantly higher uterine artery resistance indexes compared to those carrying the I/I genotype, while women with I/D genotype had intermediate indexes (30). In addition, the values of umbilical artery pulsatility in women with the D/D genotype were indeed higher compared to women of the I/D and I/I group (30).

\section{The $A C E$ I/D Polymorphism in Pre-eclampsia}

Presented as a pregnancy complication, preeclampsia (PE) is an idiopathic multisystem condition characterized by newonset hypertension $(\geq 140 / 90 \mathrm{mmHg})$, combined with proteinuria ( $\geq 300 \mathrm{mg} / 24 \mathrm{~h}$ ) after 20 weeks of gestation (31, 32 ), in addition to renal and placental morphological anomalies (4). PE is a primary cause of fetal and maternal morbidity, since it occurs in about $10 \%$ of pregnancies (33, 34). Depending on blood pressure levels, PE can be classified as mild or severe and by the onset-time of clinical symptoms as early ( $<34$ weeks) or late ( $\geq 34$ weeks) (35). Early PE includes abnormal placentation and maternal complications, while late PE is often milder and is related to pre-existing conditions of the mother's health, like diabetes mellitus (35). Having experienced PE, mothers are in a greater risk of developing cardiovascular and renal diseases or diabetes during later stages of life, with the same risk level applying to the newborns, too (32).

$\mathrm{PE}$ belongs to the spectrum of hypertensive disorders with many genes contributing to its development, but the malfunction of RAS plays a central role in its pathogenesis. Especially, the elevated levels of the key RAS enzyme ACE due to the $\mathrm{D}$ allele of the I/D polymorphism may be devastating. Histological findings of placental villi disruption and abnormal umbilical cord formation have been detected in women with the D/D genotype that experienced PE $(36,37)$.

According to three studies involving cumulatively about 1900 women from Brazil, Mexico and China, the D allele variant is the predominant one among preeclamptic women compared to the normotensive groups, suggesting that the $\mathrm{D} / \mathrm{D}$ genotype may serve as a molecular marker for women at risk for $\mathrm{PE}(34,36,38)$. Other factors that might contribute to PE pathogenesis, when coupled with the I/D polymorphism, are body mass index (BMI) and oxidative damage (36). In contrast, two other studies have failed to show the combined effect of $A C E$ I/D with polymorphisms in $G$ protein subunit Beta 3 (GNB3) and estrogen receptor 1 (ESR1) genes in the occurrence of PE $(35,39)$.

Furthermore, four studies have analysed the combined effect of $A C E \mathrm{I} / \mathrm{D}$ and $A T 1 R$ A1166C polymorphisms in PE development but they only observed a strong association of the I/D polymorphism with PE susceptibility $(33,40-42)$. One of them has reported that the DD genotype is common in preeclamptic women with severe proteinuria, renal dysfunction and high serum uric acid (41), while another study has found that the ID genotype is common in patients with mild PE and a decrease of the total antioxidant capacity (42). It seems that the combined effect of several polymorphisms with the $A C E \mathrm{I} / \mathrm{D}$, including $A T 1 R$ A1166C, $A T 2 R$ G1332A and matrix metalloproteinase 9 (MMP-9) $\mathrm{C} 1562 \mathrm{~T}$, contributes to the risk of preeclampsia pathogenesis. Particularly, this occurs when the $A T 2 R \mathrm{G}$ allele interacts in an epistatic way with each one of the $A C E \mathrm{D}, A T 1 R \mathrm{C}$, and $M M P-9$ T alleles (43). The risk of PE is highly increased when there are certain combinations of both the maternal and fetal genotypes, as shown by a study of preeclamptic mothers and their newborns that reported the importance of $A C E \mathrm{I} / \mathrm{D}$, $A C E$ A2350G, AGT Met235Thr, ATIR A1166C and REN 83A/G polymorphisms (44).

\section{The ACE I/D polymorphism in recurrent pregnancy loss}

Recurrent pregnancy loss (RPL), recurrent miscarriage (RM) or habitual abortion, involves three or more consecutive pregnancy losses before the $20^{\text {th }}$ week of gestation $(45,46)$. RPL is one of the most severe pregnancy complications, affecting about $15 \%$ of all pregnancies and representing a challenge for up to $2 \%$ of reproductively active women $(45,46)$. 
The etiology of RPL is still unclear since it is a multifactorial disorder affected by the interaction of environmental and genetic factors, such as gene polymorphisms, chromosomal anomalies and, in some cases, by inherited or acquired thrombophilia $(10,47,48)$. Abnormalities in fetal implantation and development, and most importantly in placental and fetal vasculature, may lead to gestational disturbance and eventually miscarriage (47). In fact, pregnancy complications and up to $60 \%$ of spontaneous abortions are considered to be thromboembolic incidents (49).

Based on the previously described biological role of RAS in pregnancy and in the light of the close relationship between ACE and plasminogen activator inhibitor-1 (PAI-1), which is crucial for fibrinolysis and embryo implantation (Figure 2), it is not surprising that the $A C E$ I/D polymorphism may be a potential susceptibility factor for RPL $(7,10,47,50)$. The ID and DD genotypes are linked to enhanced ACE levels leading to higher expression of PAI-1. The latter causes fibrin to accumulate in spiral arteries and within the intervillous spaces, increasing the risk for perfusion that may lead to gestational loss (6).

When it comes to investigating the influence of the $A C E$ I/D polymorphism in RPL occurrence, ethnicity must be taken into consideration since the results vary accordingly. More specifically, a meta-analysis of 26 case-control studies showed a strong linkage between the $A C E$ I/D polymorphism and higher RPL developing risk in Caucasian and West Asian women but not in East Asian (10). Additionally, it has been estimated that south-eastern Turkish women who carry the ID and DD genotypes of the polymorphism face a $72 \%$ elevated risk for RPL occurrence (7). The association between the $\mathrm{D}$ allele and elevated risk for RPL also derives from the results of a meta-analysis of 3,357 women, as well as from a smaller study of 127 Chinese RPL cases, which indicated the same strong linkage between the ID and DD genotypes and recurrent pregnancy loss $(47,50)$. On the contrary, two other studies have suggested lack of association between the ACE I/D polymorphism and RPL risk in Saudi and Slovenian women $(6,51)$.

Some studies have investigated the possible association of RPL with the coexistence of the ACE I/D and a number of other well-studied polymorphisms. A study in Korean women has reported that $A C E \mathrm{I} / \mathrm{D}, A T 1 R$ A1166C and $A G T$ M235T polymorphisms conferred a combined increased risk for idiopathic RPL (52). Additionally, another study has observed a significant influence of the $A C E \mathrm{DD}$ genotype in $A T 1 R$ C allele carriers regarding the risk for $1^{\text {st }}$ trimester fetal loss (53). Three studies in Polish, American and Korean women have reported that there was no association between the coexistence of the $A C E \quad \mathrm{I} / \mathrm{D}$ and $P A I-1 \quad 4 \mathrm{G} / 5 \mathrm{G}$ polymorphisms with the risk for RPL (54-56). Another study of 49 unrelated Caucasian women has detected a strong association between RPL susceptibility and the combination of the ACE DD genotype and the PAI-1 $4 \mathrm{G}$ and/or F13 34Leu alleles. In fact, it is mentioned that the determination of the latter polymorphisms is guaranteed to rank women positive in a high-risk group for RPL (57).

\section{The ACE I/D Polymorphism in Preterm Birth}

Preterm birth (PTB), also known as premature birth, can be described as the birth of an alive neonate, prior to the completion of the 37 weeks of pregnancy. Globally, newborn mortality, morbidity, and hospitalization are predominately adverse consequences of preterm delivery (58). It is estimated that more than 1 million preterm neonates die each year of various PTB complications, a figure which accounts for about one third of neonatal deaths (59). Many PTB survivors have visual and hearing problems and, in some cases, learning disabilities later in life $(59,60)$.

PTB is caused by various factors, including abnormal placentation, inflammatory conditions, gestational bleeding, cervical and uterine abnormalities, as well as genetic factors $(61,62)$. PTB has also been associated with blood pressure dysregulation during pregnancy, involving RAS and ACE in particular, while some studies have specifically suggested involvement of the $A C E \mathrm{I} / \mathrm{D}$ polymorphism $(58,61,62)$.

A meta-analysis of 4 studies including 928 individuals (369 PTB cases and 559 controls) has revealed a significant association between $A C E \mathrm{D}$ allele carrier status and risk for PTB in various populations (58). On the contrary, another study in Korean women (111 PTB cases and 143 controls) have not observed such an association (62).

\section{The Effect of the $A C E$ I/D Polymorphism on the Health of Preterm Infants}

Several studies have investigated the effects of the ACE I/D polymorphism in clinical outcomes of prematurely born infants. A genotyping study of 85 prematurely born infants has found an association between the ACE I/D polymorphism and greater disease severity in the first 7 days after birth (63). More specifically, the DD genotype seems to confer a higher serum ACE activity and a more severe disease status (63).

On the other hand, there has been no significant association between the $A C E \mathrm{I} / \mathrm{D}$ polymorphism and arterial hypotension in premature infants with early onset bacterial infections, as infants with different variants (II, ID and DD) tend to have similar indexes concerning hemodynamic parameters contributing to arterial hypotension (64). There is also no association of the $A C E \mathrm{D}$ allele with bronchopulmonary dysplasia in ventilated low-weight preterm neonates, regarding oxygen dependency, relative infant mortality or both (65).

Nevertheless, the $A C E$ DD genotype leads to greater ACE activity, which is linked to worse perinatal cardiopulmonary adaptation in premature newborns of 29 
to 32 weeks, contributing to the development of cardiorespiratory disease (66).

Interestingly, the combined effect of the $A C E \mathrm{I} / \mathrm{D}$ and the endothelial nitric oxide synthase 3 gene $(e N O S) 4 \mathrm{a} / \mathrm{b}$ polymorphisms may have a lethal outcome of underweight preterm infants who experience intraventricular haemorrhage (IVH). A Ukrainian study has reported that the genotype carrier status combination of both ACE D and eNOS 4a alleles highly increases the risk for IVH in premature newborns (67). IVH is usually asymptomatic or slightly symptomatic and the diagnosis requires screening cranial ultrasound (68). Therefore, knowledge of a preterm neonate's genotype regarding those polymorphisms may prove to be a lifesaver in the management of initially mild symptoms of progressive and severe IVH, so that early treatment can be provided.

\section{Discussion}

The RAS not only plays a key role in the regulation of blood pressure in general $(12,13,69)$, but it also plays a most significant role during gestation locally $(3,4)$. As a crucial component of RAS, the ACE has a significant impact on the uteroplacental structure and function and is, therefore, of great importance for the deeper understanding of major pregnancy complications.

Abnormally increased levels of ACE may be associated with gestational complications, such as preeclampsia, recurrent pregnancy loss, preterm birth and deteriorated health status of prematurely born infants $(10,34,36,38,47$, $50,58,63,66)$. A well-studied polymorphism of the ACE gene, which modifies its expression and, therefore, the quantity of the enzyme in plasma and tissue, is the I/D polymorphism $(26,27)$. The $\mathrm{D}$ allele of the I/D polymorphism is associated with enhanced ACE levels, which can lead to higher blood pressure and decreased fibrinolysis during pregnancy, exposing the uteroplacental health at risk $(5-7,11)$.

The investigation of the association of the $A C E$ I/D polymorphism with pregnancy complications through an indepth study of the relevant literature has revealed that especially the D allele is at a certain extent implicated in the most common of complications, as discussed in this review. The ACE DD genotype can be clearly considered as an independent risk factor for the development of preeclampsia, but its combination with other polymorphisms can also result in a higher predisposition for it. Regarding preterm birth, it has been shown that the $\mathrm{D}$ allele is associated with an elevated risk for premature labour in most studied populations (58). Preterm infants carrying the DD genotype have higher concentrations of plasma $\mathrm{ACE}$ and are prone to poor cardiopulmonary adaptation during the perinatal period and to greater disease severity during the first days of life $(63,66)$. Finally, there are conflicting reports regarding the possible association of the $A C E$ I/D polymorphism with recurrent pregnancy loss, however, these mostly describe results from women of different ethnicity and, as such, the matter is greatly unresolved $(6,10,47,50,51)$.

On the other hand, the interaction between the $A C E \mathrm{I} / \mathrm{D}$ and the AT1R A1166C polymorphisms, and especially the $\mathrm{DD}$ and $\mathrm{CC}$ genotypes, marks up the risk for 1st trimester fetal loss (53). In Korean women particularly, the coexistence of the ACE ID, AT1R A1166C and AGT M235T polymorphisms poses as a combinatory risk factor for idiopathic abortion (52). Lastly, the combination of $A C E$ I/D, PAI-1 4G/5G and F13 Val34Leu polymorphisms, and more specifically the $A C E$ DD genotype with $P A I-14 \mathrm{G}$ and/or F13-34Leu alleles, is significantly associated with a high risk for recurrent miscarriage (57). Regarding the preterm birth spectrum, it has been observed that the combined ACE I/D and eNOS 4a/b polymorphisms may be potential risk factors for neonatal mortality due to intraventricular haemorrhage, especially in premature underweight infants (67).

In conclusion, there is mounting evidence that the genetic susceptibility of a woman towards major pregnancy complications can be estimated by established genetic markers, such as the common ACE I/D polymorphism. "It is better to prevent than to cure" is an ageless guideline of the father of clinical medicine Hippocrates (70). It is, therefore, advisable that obstetricians routinely ask for prenatal genotyping with established genetic markers associated with major obstetrical syndromes in order to be able to provide proper medical attention at an early stage and prevent most of them.

\section{Conflicts of Interest}

None to declare.

\section{Authors' Contributions}

IG performed the research of the literature, first draft and figure drawing; MA performed critical text correction; $\mathrm{CY}$ was responsible for the overall setting up and the final draft.

\section{References}

1 Data on Selected Pregnancy Complications in the United States. Centers for Disease Control and Prevention, February 28, 2019. Available at: https://www.cdc.gov/reproductivehealth/ maternalinfanthealth/pregnancy-complications-data.htm

2 Mathai M, Engelbrecht SM and Bonet M: Managing complications in pregnancy and childbirth: A guide for midwives and doctors. Geneva: World Health Organization, 2017.

3 Lumbers ER and Pringle KG: Roles of the circulating reninangiotensin-aldosterone system in human pregnancy. Am J Physiol Regul Integr Comp Physiol, 306(2): R91-101, 2014. PMID: 24089380. DOI: 10.1152/ajpregu.00034.2013 
4 Irani RA and Xia Y: Renin angiotensin signaling in normal pregnancy and preeclampsia. Semin Nephrol 31(1): 47-58, 2011. PMID: 21266264. DOI: 10.1016/j.semnephrol.2010.10.005

5 Nielsen A, Schauser K and Poulsen K: The uteroplacental reninangiotensin system. Placenta 21(5-6): 468-477, 2000. PMID: 10940196. DOI: $10.1053 /$ plac. 2000.0535

6 Al-Mukaynizi FB, Alkhuriji A, Babay Z, Addar M, Aldaihan S, Alanazi $M$ and Warsy AS: Lack of association between angiotensin converting enzyme I/D polymorphism and unexplained recurrent miscarriage in Saudi Arabia. J Med Biochem 35(2): 166-174, 2016. PMID: 28356877. DOI: 10.1515/jomb-2015-0020

7 Gumus E: The powerful association of angiotensin-converting enzyme insertion/deletion polymorphism and idiopathic recurrent pregnancy loss. Ginekol Pol 89(10): 573-576, 2018. PMID: 30393847. DOI: 10.5603/gp.a2018.0098

8 Irani R and Xia Y: The functional role of the renin-angiotensin system in pregnancy and preeclampsia. Placenta 29(9): 763-771, 2008. PMID: 18687466. DOI: 10.1016/j.placenta.2008.06.011

9 Corbo RM, Ulizzi L, Piombo L and Scacchi R: Association of ACE I/D polymorphism and recurrent miscarriages in an Italian population with a pre-modern reproductive pattern. Ann Hum Biol 38(1): 102-105, 2010. PMID: 20450391. DOI: 10.3109/03014460.2010.481265

10 Aslbahar F, Neamatzadeh H, Tabatabaiee RS, Karimi-Zarchi M, Javaheri A, Mazaheri M, Foroughi E and Nasiri R: Association of angiotensin-converting enzyme insertion/deletion polymorphism with recurrent pregnancy loss: A meta-analysis of 26 case-control studies. Rev Bras Ginecol Obstet 40(10): 631641, 2018. PMID: 30352462. DOI: 10.1055/s-0038-1672137

11 Valdez-Velazquez LL, Quintero-Ramos A, Perez SA, MendozaCarrera F, Montoya-Fuentes H, Rivas F Jr, Olivares N, Celis A, Vazquez OF and Rivas F: Genetic polymorphisms of the reninangiotensin system in preterm delivery and premature rupture of membranes. J Renin Angiotensin Aldosterone Syst 8(4): 160168, 2007. PMID: 18205094. DOI: 10.3317/jraas.2007.026

12 Patel S, Rauf A, Khan H and Abu-Izneid T: Renin-angiotensinaldosterone (RAAS): The ubiquitous system for homeostasis and pathologies. Biomed Pharmacother 94: 317-325, 2017. PMID: 28772209. DOI: 10.1016/j.biopha.2017.07.091

13 Zhang F, Liu H, Liu D, Liu Y, Li H, Tan X, Liu F, Peng Y and Zhang $\mathrm{H}$ : Effects of raas inhibitors in patients with kidney disease. Curr Hypertens Rep 19(9): 72, 2017. PMID: 28791529. DOI: 10.1007/s11906-017-0771-9

14 Tan WSD, Liao W, Zhou S, Mei D and Wong WF: Targeting the renin-angiotensin system as novel therapeutic strategy for pulmonary diseases. Curr Opin Pharmacol 40: 9-17, 2018. PMID: 29288933. DOI: 10.1016/j.coph.2017.12.002

15 Bernardi S, Michelli A, Zuolo G, Candido R and Fabris B: Update on raas modulation for the treatment of diabetic cardiovascular disease. J Diabetes Res 2016: 8917578, 2016. PMID: 27652272. DOI: 10.1155/2016/8917578

16 Capasso G, Trepiccione F and Zacchia M: The Physiology of the Loop of Henle. In: Critical Care Nephrology (Third edition). Ronco C, Bellomo R, Kellum JA, Ricci Z (eds.). Amsterdam, Elsevier, pp. 42-48, 2019. DOI: 10.1016/B978-0-323-44942-7.00008-X

17 Verdecchia P, Angeli F, Mazzotta G, Martire P, Garofoli M, Gentile $G$ and Reboldi $G$ : Aliskiren versus ramipril in hypertension. Ther Adv Cardiovasc Dis 4(3), 193-200, 2010. PMID: 20418269. DOI: 10.1177/1753944710369682
18 Lauta VM: ACE: physiopathology and role in the diagnosis and prognosis of systemic granulomatosis, neoplasms and lung toxicity caused by antineoplastic agents. Recenti Prog Med 81(9): 601-13, 1990. PMID: 2175927.

19 Balakumar P and Jagadeesh G: A century old renin-angiotensin system still grows with endless possibilities: AT1 receptor signaling cascades in cardiovascular physiopathology. Cell Signal 26(10): 2147-2160, 2014. PMID: 25007996. DOI: 10.1016/j.cellsig.2014.06.011

20 Tanaka M, Tsuchida S, Imai T, Fujii N, Miyazaki H, Ichiki T, Naruse $\mathrm{M}$ and Inagami T: Vascular response to angiotensin II is exaggerated through an upregulation of AT1 receptor in AT2 knockout mice. Biochem Biophys Res Commun 258(1): 194198, 1999. PMID: 10222259. DOI: 10.1006/bbrc.1999.0500

21 Gaddam RR, Chambers S and Bhatia M: ACE and ACE2 in inflammation: A tale of two enzymes. Inflamm Allergy Drug Targets 13(4): 224-234, 2014. PMID: 25019157. DOI: $10.2174 / 1871528113666140713164506$

22 Santos RA, Simoes e Silva AC, Magaldi AJ, Khosla MC, Cesar $\mathrm{KR}$, Passaglio KT and Baracho NC: Evidence for a physiological role of angiotensin-(1-7) in the control of hydroelectrolyte balance. Hypertension 27(4): 875-884, 1996. PMID: 8613263. DOI: 10.1161/01.hyp.27.4.875

23 Sayed-Tabatabaei FA, Oostra BA, Isaacs A, van Duijn CM and Witteman JC: ACE polymorphisms. Circ Res 98(9): 1123-1133, 2006. PMID: 16690893. DOI: 10.1161/01.res.0000223145. 74217.e7

24 Coates D: The angiotensin converting enzyme (ACE). Int J Biochem Cell Biol 35(6): 769-773, 2003. PMID: 12676162. DOI: $10.1016 / \mathrm{s} 1357-2725(02) 00309-6$

25 Moradzadegan A, Vaisi-Raygani A, Nikzamir A and Rahimi Z: Angiotensin converting enzyme insertion/deletion (I/D) (rs4646994) and VEGF polymorphism (+405g/c; rs2010963) in type II diabetic patients: Association with the risk of coronary artery disease. J Renin Angiotensin Aldosterone Syst 16(3): 672680, 2014. PMID: 24505095. DOI: 10.1177/1470320313497819

26 Yapijakis C, Koronellos N, Spyridonidou S, Vylliotis A, Avgoustidis D, Goutas N, Vlachodimitropoulos D and Vairaktaris E: Association of angiotensin-converting enzyme gene insertion/deletion polymorphism with decreased risk for basal cell carcinoma. Arch Dermatol Res 305(4): 333-339, 2013. PMID: 23299466. DOI: 10.1007/s00403-012-1312-7

27 Shahmoradi S, Ahmadalipour A and Salehi M: Evaluation of ACE gene I/D polymorphism in Iranian elite athletes. Adv Biomed Res 3(1): 207, 2014. PMID: 25371864. DOI: 10.4103/22779175.143242

28 Howie PW: Blood clotting and fibrinolysis in pregnancy. Postgrad Med J 55(643): 362-266, 1979. PMID: 382169. DOI: 10.1136/pgmj.55.643.362

29 Binder ND, Laird MR and Faber JJ: Interrelationships between the renin angiotensin system and uteroplacental blood flow - a recent perspective. Reprod Fertil Dev 7(6): 1437-1442, 1995. PMID: 8743144. DOI: 10.1071/rd9951437

30 Mello G, Parretti E, Gensini F, Sticchi E, Mecacci F, Scarselli G, Genuardi M, Abbate R and Fatini C: Maternal-fetal flow, negative events, and preeclampsia. Hypertension 41(4): 932-937, 2003. PMID: 12654717. DOI: 10.1161/01.hyp.0000063146.40351.ad

31 Duley L: The global impact of pre-eclampsia and eclampsia. Semin Perinatol 33(3): 130-137, 2009. PMID: 19464502. DOI: 10.1053/j.semperi.2009.02.010 
32 Procopciuc LM, Nemeti G, Buzdugan E, Iancu M, Stamatian F and Caracostea G: Renin-angiotensin system gene variants and risk of early- and late-onset preeclampsia: A single center casecontrol study. Pregnancy Hypertension 18: 1-8, 2019. PMID: 31442828. DOI: 10.1016/j.preghy.2019.08.006

33 Timokhina EV, Strizhakov AN, Ignatko IV, Belousova VS and Ibragimova SM: Genetic aspects of preeclampsia: The role of polymorphisms in the genes of the renin-angiotensin system. Biochemistry 84(2): 181-186, 2019. PMID: 31216977. DOI: $10.1134 / \mathrm{s} 0006297919020093$

34 Velloso EP, Vieira R, Cabral AC, Kalapothakis E and Santos RA: Reduced plasma levels of angiotensin-(1-7) and renin activity in preeclamptic patients are associated with the angiotensin Iconverting enzyme deletion/deletion genotype. Braz J Med Biol Res 40(4): 583-590, 2007. PMID: 17401503. DOI: 10.1590/s0100-879x2007000400018

35 Cristina Dos Santos Lopes A, Perucci LO, Gontijo Evangelista FC, Godoi LC, de Paula Sabino A, Gomes KB, Talvani A, Dusse LMS and Alpoim PN: Association among ACE, ESR1 polymorphisms and preeclampsia in Brazilian pregnant women. Mol Cell Probes 45: 43-47, 2019. PMID: 31028794. DOI: 10.1016/j.mcp.2019.04.004

36 González-Garrido JA, García-Sánchez JR, Tovar-Rodríguez JM and Olivares-Corichi IM: Preeclampsia is associated with ACE I/D polymorphism, obesity and oxidative damage in Mexican women. Pregnancy Hypertension 10: 22-27, 2017. PMID: 29153683. DOI: 10.1016/j.preghy.2017.04.001

37 Shaheen G, Sajid S, Razak S, Mazhar SB, Afsar T, Almajwal A, Alam I and Jahan S: Role of ACE I/D polymorphism in pathological assessment of preeclampsia in Pakistan. Mol Genet Genomic Med 7(7): e00799, 2019. PMID: 31173490. DOI: $10.1002 / \mathrm{mgg} 3.799$

38 Zhong WG, Wang Y, Zhu $\mathrm{H}$ and Zhao X: Meta analysis of angiotensin-converting enzyme I/D polymorphism as a risk factor for preeclampsia in Chinese women. Genet Mol Res 11(3): 22682276, 2012. PMID: 22653650. DOI: 10.4238/2012.may.21.1

39 Ma L, Fan P, Liu XH, He GL, Liu R, Ren RM, Chen YH, Liu Y and Bai H: Interaction between GNB3 C825T and ACE I/D polymorphisms in pre-eclampsia. Sichuan Da Xue Xue Bao Yi Xue Ban 46(1): 118-122, 2015. PMID: 25807809.

40 Salimi S, Mokhtari M, Yaghmaei M, Jamshidi M and Naghavi A: Association of angiotensin-converting enzyme intron 16 insertion/deletion and angiotensin II type 1 receptor A1166C gene polymorphisms with preeclampsia in south east of Iran. J Biomed Biotechnol 2011: 941515, 2011. PMID: 21808598. DOI: 10.1155/2011/941515

$41 \mathrm{Li} \mathrm{H}, \mathrm{Ma}$ Y, Fu Q and Wang L: Angiotensin-converting enzyme insertion/deletion (ACE I/D) and angiotensin II type 1 receptor (AT1R) gene polymorphism and its association with preeclampsia in Chinese women. Hypertens Pregnancy 26(3): 293-301, 2007. PMID: 17710578. DOI: 10.1080/106419 50701413676

42 Rahimi Z, Rahimi Z, Mozafari H and Parsian A: Preeclampsia and angiotensin converting enzyme (ACE) I/D and angiotensin II type-1 receptor (AT1R) A1166C polymorphisms: Association with ACE I/D polymorphism. J Renin Angiotensin Aldosterone Syst 14(2): 174-180, 2012. PMID: 22719026. DOI: $10.1177 / 1470320312448950$

43 Rahimi Z, Rahimi Z, Aghaei A and Vaisi-Raygani A: AT2R -1332 G:A polymorphism and its interaction with AT1R 1166
A:C, ACE I/D and MMP-9 -1562 C:T polymorphisms: Risk factors for susceptibility to preeclampsia. Gene 538(1): 176-181, 2014. PMID: 24440243. DOI: 10.1016/j.gene.2013.12.013

44 Procopciuc LM, Caracostea G, Zaharie G, Puscas M, Iordache G, Popa M, Colcear D, Olteanu I and Stamatian F: Maternal/newborn genotype contribution of the renin-angiotensin system (Met235Thr, Thr174Met, I/D-ACE, A2350G-ACE, A1166CAT2R1, C3123A- AT2R2, 83A/G-REN) to the risk of preeclampsia: A Romanian study. J Renin Angiotensin Aldosterone Syst 12(4): 539-548, 2011. PMID: 21436209. DOI: 10.1177/147 0320311399603

45 Ford HB and Schust DJ: Recurrent pregnancy loss: Etiology, diagnosis, and therapy. Rev Obstet Gynecol 2(2): 76-83, 2009. PMID: 19609401

46 Baek KH, Lee EJ and Kim YS: Recurrent pregnancy loss: The key potential mechanisms. Trends Mol Med 13(7): 310-317, 2007. PMID: 17574920. DOI: 10.1016/j.molmed.2007.05.005

47 Wang Z, Wang P, Wang X, He X, Wang Z, Xu D, Hu J and Wang B: Significant association between angiotensin-converting enzyme gene insertion/deletion polymorphism and risk of recurrent miscarriage: A systematic review and meta-analysis. Metabolism 62(9): 1227-1238, 2013. PMID: 23850180. DOI: 10.1016/j.metabol.2013.03.003

48 McNamee K, Dawood F and Farquharson R: Recurrent miscarriage and thrombophilia: an update. Curr Opin Obstet Gynecol 24(4): 229-234, 2012. PMID: 22729089. DOI: $10.1097 /$ gco.0b013e32835585dc

49 Yapijakis C, Antoniadi T, Salavoura K, Voumvourakis C and Vairaktaris E: Potential prevention of thromboembolism by genetic counseling and testing for two common thrombophilia mutations. In Vivo 26(1): 165-172, 2012. PMID: 22210734

50 Zhang S, Wang J, Wang B, Ping Y and Ma X: Strong association between angiotensin I-converting enzyme I/D polymorphism and unexplained recurrent miscarriage of Chinese women-a case-control study. Reprod Sci 18(8): 743-746, 2011. PMID: 21795738. DOI: 10.1177/1933719111415865

51 Pereza N, Ostojić S, Zdravčević M, Volk M, Kapović M and Peterlin B: Insertion/deletion polymorphism in intron 16 of ACE gene in idiopathic recurrent spontaneous abortion: Case-control study, systematic review and meta-analysis. Reprod Biomed Online 32(2): 237-246, 2016. PMID: 26673102. DOI: 10.1016/j.rbmo.2015.11.003

52 Choi YS, Kwon H, Kim JH, Shin JE, Choi Y, Yoon TK, Choi DH and Kim NK: Haplotype-based association of ACE I/D, AT1R 1166AC, and AGT M235T polymorphisms in reninangiotensin-aldosterone system genes in Korean women with idiopathic recurrent spontaneous abortions. Eur J Obstet Gynecol Reprod Biol 158(2): 225-228, 2011. PMID: 21636204. DOI: 10.1016/j.ejogrb.2011.04.028

53 Fatini C, Gensini F, Battaglini B, Prisco D, Cellai AP, Fedi S, Marcucci R, Brunelli T, Mello G, Parretti E, Pepe G and Abbate $\mathrm{R}$ : Angiotensin-converting enzyme DD genotype, angiotensin type 1 receptor $\mathrm{CC}$ genotype, and hyperhomocysteinemia increase first-trimester fetal-loss susceptibility. Blood Coagul Fibrinolysis 11(7): 657-662, 2000. PMID: 11085286. DOI: 10.1097/00001721-200010000-00010

54 Kurzawińska G, Barlik M, Drews K, Różycka A, SeremakMrozikiewicz A, Ożarowski M, Klejewski A, Czerny B and Wolski $\mathrm{H}$ : Coexistence of ACE (I/D) and PAI-1(4G/5G) gene variants in recurrent miscarriage in Polish population. Ginekol Pol 87(4): 271276, 2016. PMID: 27321098. DOI: 10.17772/gp/62203 
55 Goodman C, Hur J, Goodman CS, Jeyendran RS and Coulam C: Are polymorphisms in the ACE and PAI-1 genes associated with recurrent spontaneous miscarriages? Am J Reprod Immunol 62(6): 365-370, 2009. PMID: 19821806. DOI: 10.1111/j.16000897.2009.00744.x

56 Kim JJ, Choi YM, Lee SK, Yang KM, Paik EC, Jeong HJ, Jun JK, Han AR and Hong MA: The PAI-1 4G/5G and ACE I/D polymorphisms and risk of recurrent pregnancy loss: A casecontrol study. Am J Reprod Immunol 72(6): 571-576, 2014. PMID: 25078885. DOI: 10.1111/aji.12302

57 Dossenbach-Glaninger A, van Trotsenburg M, Schneider B, Oberkanins C and Hopmeier P: ACE I/D polymorphism and recurrent first trimester pregnancy loss: Interaction with SERPINE1 4G/5G and F13 Val34Leu polymorphisms. Br J Haematol 141(2): 269-271, 2008. PMID: 18318764. DOI: $10.1111 / \mathrm{j} .1365-2141.2008 .07058 . x$

58 Hočevar K, Peterlin A, Jovanović AM, Božović A, Ristanović $\mathrm{M}$, Tul N and Peterlin B: Association between angiotensinconverting enzyme gene insertion/deletion polymorphism and susceptibility to preterm birth: A case-control study and metaanalysis. Eur J Obstet Gynecol Reprod Biol 231: 122-128, 2018. PMID: 30366344. DOI: 10.1016/j.ejogrb.2018.09.019

59 Liu L, Oza S, Hogan D, Chu Y, Perin J, Zhu J, Lawn JE, Cousens S, Mathers C and Black RE: Global, regional, and national causes of under-5 mortality in 2000-15: An updated systematic analysis with implications for the Sustainable Development Goals. Lancet 388(10063): 3027-3035, 2016. PMID: 27839855. DOI: 10.1016/s0140-6736(16)31593-8

60 World Health Organization (2018) Preterm birth. Available at https://www.who.int/news-room/fact-sheets/detail/preterm-birth

61 Uma R, Forsyth JS, Struthers AD, Fraser CG, Godfrey V and Murphy DJ: Correlation of angiotensin converting enzyme activity and the genotypes of the I/D polymorphism in the ACE gene with preterm birth and birth weight. Eur J Obstet Gynecol Reprod Biol 141(1): 27-30, 2008. PMID: 18755533. DOI: 10.1016/j.ejogrb.2008.07.006

62 Lee NR, Hwang IW, Kim HJ, Kang YD, Park JW and Jin HJ: Genetic association of angiotensin-converting enzyme (ACE) gene I/D polymorphism with preterm birth in Korean women: Case-control study and meta-analysis. Medicina 55(6): 264, 2019. PMID: 31185683 . DOI: 10.3390/medicina55060264
63 Han TY, Li ZL and Ye HM: Relationship of the disease severity with ACE gene polymorphism and serum ACE activity in preterm infants. Zhongguo Dang Dai Er Ke Za Zhi 10(6): 693696. PMID: 19102831.

64 Kovaleva E, Pokhylko V, Chernyavskaya Y, Kalyuzka E and Poltoropavlov V: Analysis of the associations between angiotensinconverting enzyme gene polymorphism and arterial hypotension in premature infants with early onset bacterial infections. Georgian Med News 248: 60-68, 2015. PMID: 26656553.

65 Yanamandra $\mathrm{K}$, Loggins $\mathrm{J}$ and Baier RJ: The angiotensin converting enzyme insertion/deletion polymorphism is not associated with an increased risk of death or bronchopulmonary dysplasia in ventilated very low birth weight infants. BMC Pediatr 4: 26, 2004. DOI: 10.1186/1471-2431-4-26

66 Harding D, Dhamrait S, Marlow N, Whitelaw A, Gupta S, Humphries S and Montgomery H: Angiotensin-converting enzyme DD genotype is associated with worse perinatal cardiorespiratory adaptation in preterm infants. J Pediatr 143(6): 746-749, 2003. PMID: 14657821. DOI: 10.1067/s0022-3476(03)00582-1

67 Гасюк НИ, Артемова НС, Ковалева ЕМ, Похилько ВИ, Соловьева ГА: The role of genes of renin-angiotensin system in the development of adverse outcomes of treatment in severe intraventricular hemorrhages in premature infants. Wiad Lek 71(1 pt 2): 148-154, 2018. PMID: 29602923.

68 Ballabh P: Intraventricular hemorrhage in premature infants: Mechanism of disease. Pediatr. Res 67(1): 1-8. PMID: 19816235. DOI: 10.1203/pdr.0b013e3181c1b176

69 Mocan O, Radulescu D, Buzdugan E, Cozma A, Leucuta DC and Procopciuc LM: Association between M235T-AGT and I/DACE polymorphisms and carotid atheromatosis in hypertensive patients: A cross-sectional study. In Vivo 34(5): 2811-2819, 2020. PMID: 32871819. DOI:10.21873/invivo.12107

70 Yapijakis C: Hippocrates of Kos, the father of clinical medicine, and Asclepiades of Bithynia, the father of molecular medicine. In Vivo 23(4): 507-514, 2009. PMID: 19567383.

Received October 13, 2020

Revised November 6, 2020

Accepted November 9, 2020 